\title{
PHYSICAL ACTIVITY AND SEDENTARY SCREEN TIME IN OBESE AND OVERWEIGHT CHILDREN LIVING IN DIFFERENT ENVIRONMENTS
}

\author{
Juozas Raistenskis ${ }^{1}$, Aurelija Sidlauskiene ${ }^{1}$, Rimante Cerkauskiene ${ }^{2}$, Sigita Burokiene ${ }^{2}$, Birute Strukcinskiene ${ }^{3}$, \\ Raimondas Buckus ${ }^{4}$ \\ 'Department of Rehabilitation, Physical and Sports Medicine, Faculty of Medicine, Vilnius University, Vilnius, Lithuania \\ ${ }^{2}$ Clinic of Children's Diseases, Faculty of Medicine, Vilnius University, Vilnius, Lithuania \\ ${ }^{3}$ Faculty of Health Sciences, Klaipeda University, Klaipeda, Lithuania \\ ${ }^{4}$ Public Health Institute, Faculty of Medicine, Vilnius University, Vilnius, Lithuania
}

\begin{abstract}
SUMMARY
Aim: To assess the relationship of children's physical activity and sedentary screen time with overweight and obesity in children living in different environments (town and city) in Lithuania.

Methods: An analysis of anthropometric data from 532 children living in town and city areas was performed. A youth physical activity questionnaire (YPAQ) was conducted to evaluate physical activity and sedentary screen time.

Results: The prevalence of overweight and obesity among the children was $25.5 \%$ in the town and $18.6 \%$ in the city. Children living in the town on average engaged $9.3 \mathrm{~min} /$ day less in moderate to vigorous physical activity $(p=0.050)$ and had $33.2 \mathrm{MET}$-min/day lower energy expenditure than children living in the city. Sedentary screen time was extremely high on weekends in both town and city children.

Conclusions: A higher prevalence of overweight and obesity and a lower amount of moderate-to-vigorous physical activity was found in children living in the town compared to children living in the city.
\end{abstract}

Key words: obesity, physical activity, sedentary screen time, town, city, children

Address for correspondence: A. Sidlauskiene, Faculty of Medicine, Vilnius University, Ciurlionio st. 21, LT-03101 Vilnius, Lithuania. E-mail: aurelija.sidlauskiene@vuvl.It

\section{INTRODUCTION}

Physical activity, sedentary behaviour of children and childhood overweight are among the most important current public health concerns (1-6). Several factors contribute to the imbalance between energy intake and energy expenditure that influences weight gain (1).

In childhood physical activity and sedentary behaviour habits begin to form (2). Levels of habitual physical activity and sedentary behaviour are well established as important to both the current and future health of children and adolescents (3-5). However, studies reveal that physical activity declines before adolescence (6).

Research has highlighted important socioeconomic differences in children's physical activity. For instance, youth from higher socioeconomic backgrounds have been found to engage in more physical activities than youth from lower socioeconomic backgrounds (7). However, studies that assess the prevalence of obesity and physical activity in children living in different environments have yielded controversial results. Some studies show higher prevalence of overweight and obesity among rural children than urban children $(8,9)$. Hodgkin et al. on the contrary reported that urban children were 1.3-1.4 times more likely to be overweight or obese than rural children (10). A systematic review by Sandercock et al. (11) showed that rural children were significantly more active than urban children. Studies carried out in Canada $(12-14)$ and Australia $(15,16)$ found no significant difference in physical activity between rural and urban children. Kristjansdottir and Vilhjalmsson found that rural students in Iceland were more sedentary and less involved in strenuous exercise during their leisure time than students in urban areas. The authors suggest that relatively high activity levels among students in town may perhaps be explained by good sports facilities and a strong emphasis on youth sport in many municipalities as well as by the absence of many leisure time attractions found in metropolitan areas (17).

Ogunleye et al. suggest that simple rural versus urban divisions of environment may be too simplistic to study physical activity patterns in youth. Specifically, classifying suburban (or town and fringe) along with rural areas may be misleading. At least a trilateral division of the environment, including suburban areas as a discrete classification, appears preferable (18).

Suburban or town contexts are often neglected in research. Suburban neighbourhoods have characteristics of both rural and urban environments and they are better connected to urban centres than rural environments, yet they may sit at a distance from points of interest that are not within walking distance (19). Ogunleye et al. concluded that town and fringe environments appear to support physical activity in both children and adolescents. More importantly, these environments appear to attenuate the reduction in physical activity commonly observed between childhood and 
adolescence (18). Therefore, the aim of this study was to assess the relationship of children's physical activity and sedentary screen time with overweight and obesity in children living in different environments (town and city) in Lithuania. The objectives of the study were to assess the prevalence of children's overweight and obesity in different environments; to evaluate the duration of children's moderate to vigorous physical activity, energy expenditure and sedentary screen time in different environments; and to analyse the correlations between children's physical activity, sedentary screen time and anthropometric data.

\section{MATERIALS AND METHODS}

\section{Study Population}

The cross sectional study was performed at three Eastern Lithuanian schools: two schools in the town and one school in the city. All children from the 5th-7th grades were invited to participate in the study. The study population consisted of 118 children living in the town and 414 children living in the city (total $\mathrm{n}=532)$, aged from $11-14$ years $(12.99 \pm 0.96)$. In our study we used two categories of living place/living environment: "town" and "city". Category "rural" (or "village") is another category that has not been explored in this study. A town is a settlement larger than a village but smaller than a city. According to the Law of Republic of Lithuania on territorial administrative units and their boundaries, a town has 500 to 3,000 inhabitants.

The study was conducted with the approval of the Lithuanian Bioethics Committee (Protocol No.1, 6/4/2003). Written informed consent was obtained from the parents of each participating child.

\section{Anthropometric Measurements Body Mass Index (BMI)}

Body height was measured according to the standard procedure, with the children standing upright, without shoes, with hips and shoulders perpendicular to the central axis, feet and knees together, and the head in the Frankfurt plane to the nearest 0.5 $\mathrm{cm}$. Body weight was measured using a doctor's scale to the nearest $0.5 \mathrm{~kg}$. Body mass index was calculated as body weight in kilograms divided by body height in square metres.

Obesity, overweight, normal weight, and underweight were defined according to WHO child growth characteristics (20).

\section{Waist to Hip Ratio (WHR)}

Waist circumference (WC) was measured to the nearest $0.5 \mathrm{~cm}$ at the midpoint between the lower border of the rib cage and the iliac crest at the end of a normal expiration. Hip circumference (HC) was measured to the nearest $0.5 \mathrm{~cm}$ at the widest part of the hip at the greater trochanter. WHR was calculated by dividing WC by HC (21).

\section{Body Fat (\%)}

Skinfold thickness was measured to the nearest $0.5 \mathrm{~mm}$ by using a Saehan calliper. Triceps (midway between the olecranon process and the acromion process on the posterior aspect of the arm) and subscapular (the inferior angle of the scapula) skinfold thickness was measured by highly trained technicians following recommended procedures (22). All measurements were taken on the right side of the body. Body fat percentages were calculated with the following formulas (23):

Body fat $(\%)$ for children with triceps and subscapular skinfolds $<35 \mathrm{~mm}$ :

Boys $=1.21$ (sum of 2 skinfolds $)-0.008(\text { sum of } 2 \text { skinfolds })^{2}-3.4$ Girls $=1.33$ (sum of 2 skinfolds) -0.013 (sum of 2 skinfolds) ${ }^{2}-2.5$

Body fat $(\%)$ for children with triceps and subscapular skinfolds $>35 \mathrm{~mm}$ :

Boys $=0.783$ (sum of 2 skinfolds $)+1.6$

Girls $=0.546$ (sum of 2 skinfolds $)+9.7$

\section{Assessment of Physical Activity and Sedentary Screen Time}

A youth physical activity questionnaire (YPAQ) was used to assess physical activity and screen sedentary time in children. YPAQ contains a list of 47 different activities, and participants are asked to report the frequency and duration of each activity over the preceding seven days. YPAQ assesses mode, frequency and duration of physical activities and sedentary activities throughout all domains, including school time and leisure time over the preceding seven days (24).

In the study the duration of time (min/day) spent on moderate to vigorous physical activity (MVPA) and sedentary screen time (SST) were used. MET (metabolic equivalent) minutes of physical activity were calculated as duration $\times$ frequency $\times$ MET intensity (25).

\section{Statistical Analyses}

In the study, descriptive statistics are presented as absolute data numbers (n) and mean with standard deviation (SD). The Kolmogorov-Smirnov test was used to check hypotheses for regularity of distribution of parameters. For comparisons of the quantitative variables of two independent groups, the parametric Student's t-test and non-parametric Mann-Whitney test were applied. Receiver operating characteristic (ROC) curves were used to find out the optimal cut-off values of moderate to vigorous physical activity and energy expenditure. Spearman's correlation coefficient ( $r$ ) was used to estimate correlations. A p-value $\leq 0.05$ was regarded as statistically significant. The data was analysed using SPSS Statistics 21.0 for Windows software.

\section{RESULTS}

The anthropometric data of children living in the town is presented in Table 1. Anthropometric data showed that boys living in the town had a higher mean value of BMI in all age groups $(20.1 \pm 4.6)$ compared with the girls' mean value of BMI (19.2 \pm 3.5$)$, but this difference was not statistically significant $(\mathrm{p}=0.236)$. It was found that the girls' mean values of WC $(63.8 \pm 7.5)$ and WHR $(0.75 \pm 0.04)$ were lower than the boys' mean values of WC $(68.2 \pm 9.9, \mathrm{p}=0.015)$ and $\mathrm{WHR}(0.79 \pm 0.05$, $\mathrm{p}<0.001)$.

Anthropometric data of the children living in the city is presented in Table 2. Boys living in the city had also higher mean value of BMI in all age groups (19.7 \pm 4.3$)$ compared with the girls' 


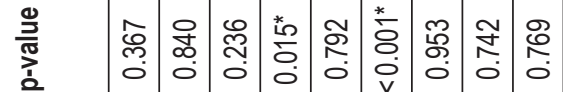

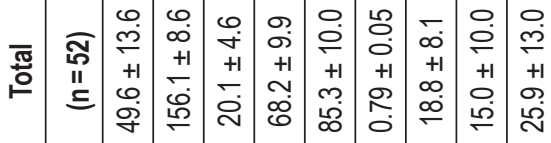

ֻ

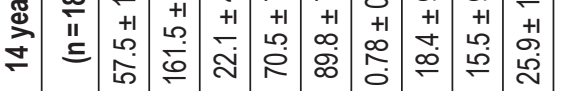

2)

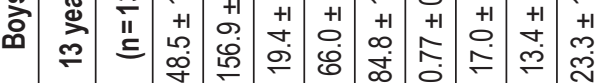

을

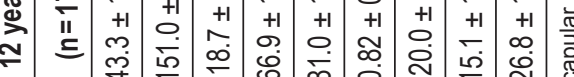

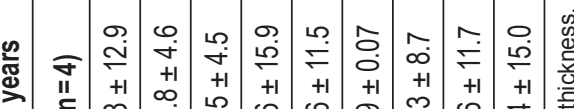

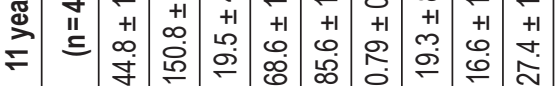

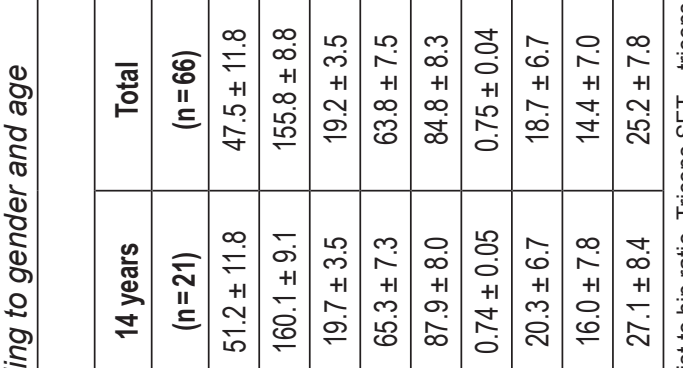

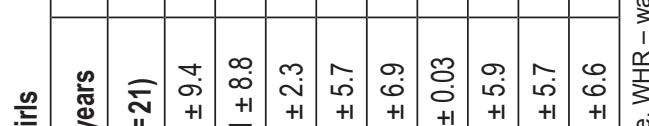

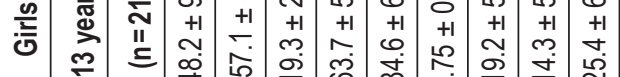

+

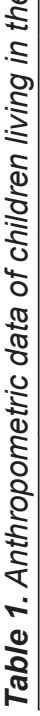

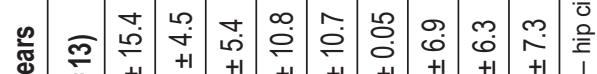

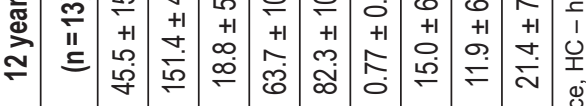

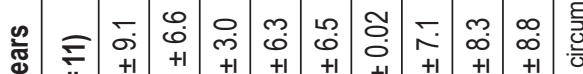

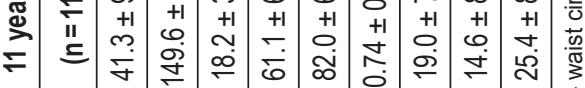

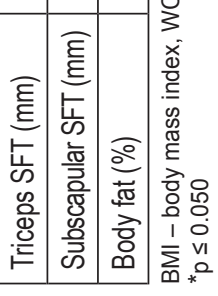

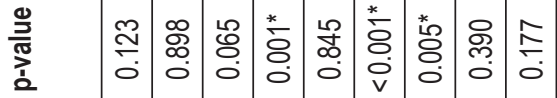

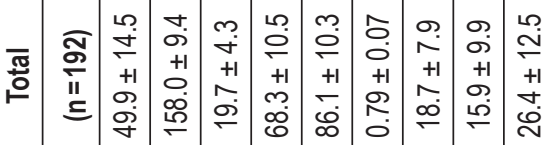

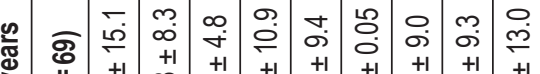

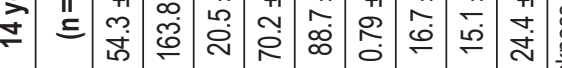

今ั

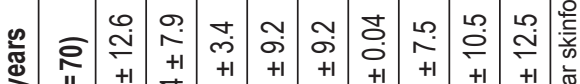

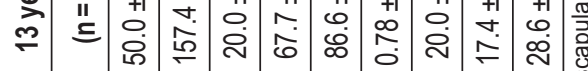

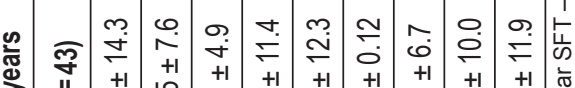

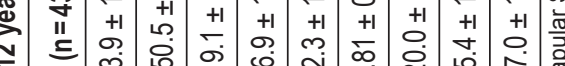

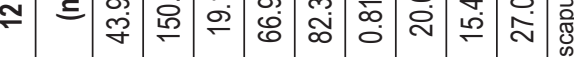

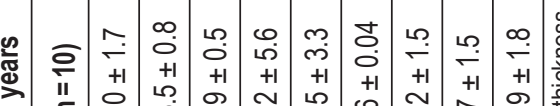

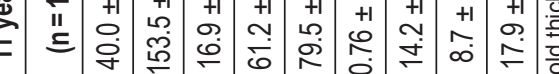

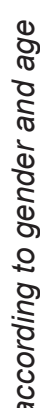

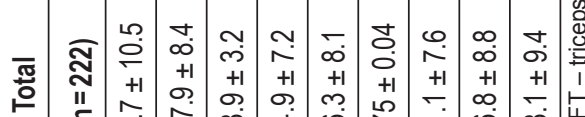

$\frac{\pi}{2}$

$\stackrel{\bar{\Phi}}{\stackrel{0}{\Phi}}$

㠃

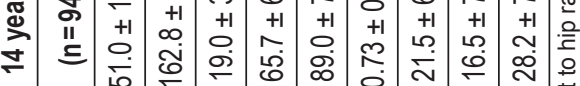

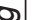

ำ

$\stackrel{1}{5}$

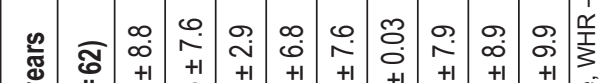

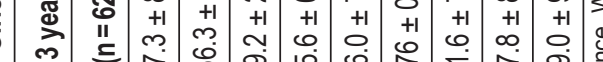

$\leq$

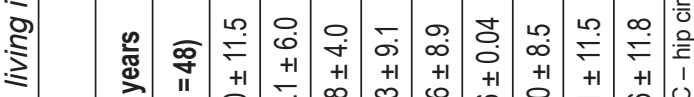

ब

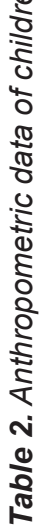

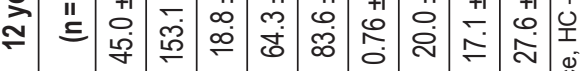

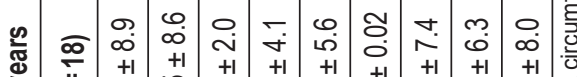

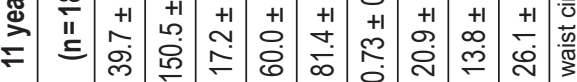

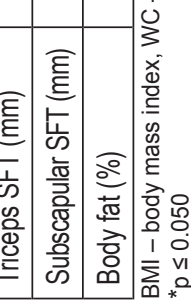


mean value of BMI $(18.9 \pm 3.2, \mathrm{p}=0.065)$. However, differently from BMI, girls had a higher mean value of the percentage of body fat $(28.1 \pm 9.4)$ than boys $(26.4 \pm 12.5)$, but this difference was not statistically significant $(\mathrm{p}=0.177)$.

The distribution of weight status in the children according to gender is presented in Table 3. The classification of weight status according to the WHO child growth characteristics (20) showed that $25.5 \%$ of children living in the town were overweight and obese, while the prevalence of overweight and obesity among children living in the city was $18.6 \%(p=0.171)$. More boys than girls were obese or overweight: $30.8 \%$ of boys living in the town and $23.9 \%$ of boys living in the city were obese or overweight, compared to $21.2 \%$ and $14.0 \%$ of girls, respectively.

The data of children's physical activity is shown in Figure 1. The physical activity assessment revealed that children living in the town engaged in MVPA for less time (89.2 $\pm 83.7 \mathrm{~min} /$ day) than children living in the city $(98.5 \pm 90.1 \mathrm{~min} /$ day $)(\mathrm{p}=0.050)$. The mean value of energy expenditure was $473.8 \pm 442.0$ MET$\mathrm{min} /$ day for children living in the town and 507.0 $\pm 388.7 \mathrm{MET}-$ $\mathrm{min} /$ day for children living in the city $(\mathrm{p}=0.069)$. Both town and city children spend less time in MVPA during weekdays compared with weekends. The mean value of time spent in MVPA on weekdays was 29.6 minutes less for children living in the town and 16.4 minutes less for children living in the city (Table 4).

The moderate to vigorous physical activity (MVPA) receiver operating characteristic (ROC) curve shows that the optimal cutoff value in the children studied was $65 \mathrm{~min} /$ day. It was found that $60.8 \%$ of children in the city and $47.7 \%$ of children in the town

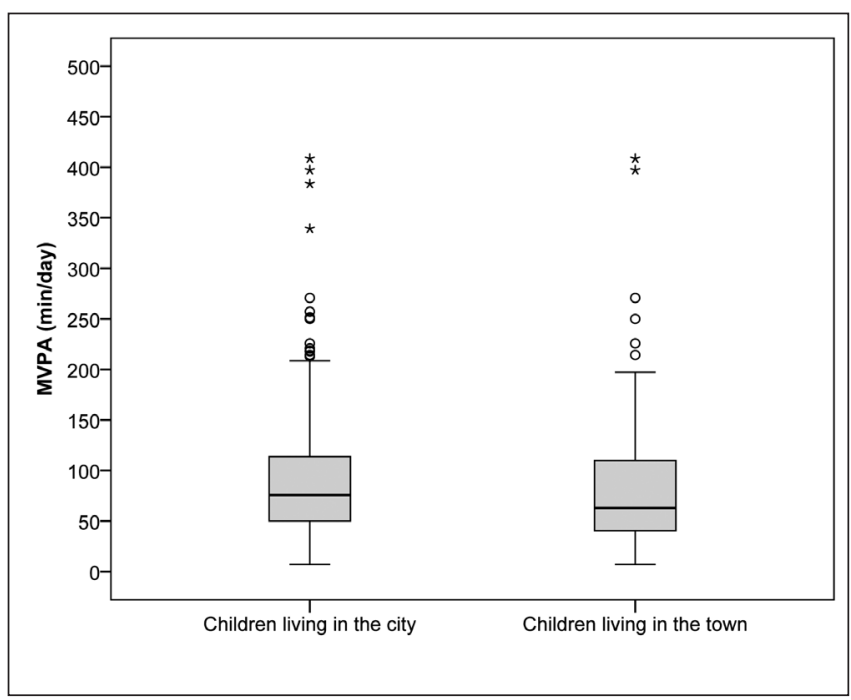

Fig. 1. Moderate to vigorous physical activity (MVPA, min/day) in children living in the city and in the town $(p=0.050)$.

engaged in MVPA for $\geq 65 \mathrm{~min} /$ day. Binary logistic regression analysis allowed predicting that the odds ratio, when MVPA is $\geq 65 \mathrm{~min} /$ day, is greater than $1.708(1.108-2.628, \mathrm{p}=0.015)$ for children living in the city.

According to the median of energy expenditure (MET-min/ day) distribution, the optimal cut-off value, $403 \mathrm{MET}$-min/day, was defined. It was found that $52.6 \%$ of children living in the city and $41.7 \%$ of children living in the town had $\geq 403 \mathrm{MET}$-min/day

Table 3. Weight status of children living in the town and the city according to gender

\begin{tabular}{|c|c|c|c|c|c|c|c|}
\hline & \multicolumn{3}{|c|}{$\begin{array}{l}\text { Children living in the town } \\
\qquad n=118\end{array}$} & \multicolumn{3}{|c|}{$\begin{array}{l}\text { Children living in the city } \\
\qquad \mathrm{n}=414\end{array}$} & \multirow{3}{*}{$p$-value } \\
\hline & Girls & Boys & Total & Girls & Boys & Total & \\
\hline & $n(\%)$ & $\mathrm{n}(\%)$ & $\mathrm{n}(\%)$ & $\mathrm{n}(\%)$ & $\mathrm{n}(\%)$ & $\mathrm{n}(\%)$ & \\
\hline Obese & $8(12.1)$ & $11(21.2)$ & $19(16.1)$ & $21(9.5)$ & $25(13.0)$ & 46 (11.1) & 0.171 \\
\hline Overweight & $6(9.1)$ & $5(9.6)$ & $11(9.3)$ & $10(4.5)$ & $21(10.9)$ & $31(7.5)$ & 0.171 \\
\hline Normal weight & 47 (71.2) & $32(61.5)$ & 79 (66.9) & $178(80.2)$ & $134(69.8)$ & $312(75.4)$ & 0.171 \\
\hline Underweight & $5(7.6)$ & $4(7.7)$ & $9(7.6)$ & $13(5.9)$ & $12(6.3)$ & $25(6.0)$ & 0.171 \\
\hline
\end{tabular}

Classified according to the WHO child growth characteristics (20)

Table 4. Moderate to vigorous physical activity (MVPA), energy expenditure, and sedentary screen time (SST) of children living in the town and in the city

\begin{tabular}{|l|c|c|c|c|c|}
\hline \multirow{2}{*}{} & \multicolumn{2}{|c|}{$\begin{array}{c}\text { Children living in the town } \\
\mathrm{n}=118\end{array}$} & \multicolumn{2}{c|}{$\begin{array}{c}\text { Children living in the city } \\
\mathrm{n}=414\end{array}$} & \multicolumn{2}{c|}{$\mathrm{p}$-value } \\
\cline { 2 - 6 } & Minimum-maximum & Mean \pm SD & Minimum-maximum & Mean \pm SD & \\
\hline MVPA (min/day) & $7.1-397.1$ & $89.2 \pm 83.7$ & $7.1-408.5$ & $98.5 \pm 90.1$ & $0.050^{*}$ \\
\hline Weekdays MVPA (min/day) & $2.0-436.0$ & $84.1 \pm 79.8$ & $2.0-436.0$ & $99.0 \pm 89.1$ & $0.003^{*}$ \\
\hline Weekends MVPA (min/day) & $5.0-510.0$ & $113.7 \pm 122.7$ & $0.5-990.0$ & $115.4 \pm 137.5$ & 0.744 \\
\hline Energy expenditure (MET-min/day) & $38.5-2482.2$ & $473.8 \pm 442.0$ & $31.4-2634.2$ & $507.0 \pm 388.7$ & 0.069 \\
\hline SST (min/day) & $2.8-591.4$ & $141.1 \pm 111.2$ & $2.8-642.8$ & $149.0 \pm 105.4$ & 0.350 \\
\hline Weekdays SST (min/day) & $2.0-612.0$ & $117.1 \pm 97.2$ & $2.0-612.0$ & $130.2 \pm 96.15$ & 0.189 \\
\hline Weekends SST (min/day) & $5.0-810.0$ & $232.7 \pm 173.2$ & $5.0-930.0$ & $246.8 \pm 170.9$ & 0.319 \\
\hline
\end{tabular}

MVPA - moderate to vigorous physical activity, MET - metabolic equivalent, SST - sedentary screen time

${ }^{*} p \leq 0.050$ 


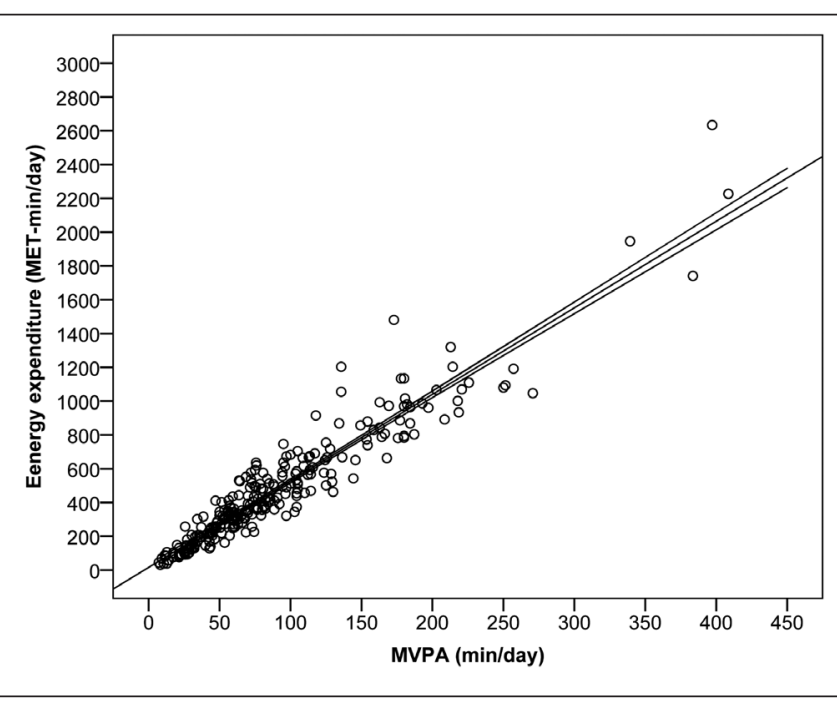

Fig. 2. Correlation between children's moderate to vigorous physical activity (MVPA, min/day) and energy expenditure (MET-min/day) $(r=0.945, p<0.001)$.

value of energy expenditure. Binary logistic regression analysis allowed predicting that the odds ratio, when energy expenditure is $\geq 403 \mathrm{MET}-\mathrm{min} /$ day, is greater than 1.547 (1.004-2.383, $\mathrm{p}=$ 0.048 ) for children living in the city.

Analysis of sedentary screen time revealed no significant difference $(p=0.350)$ in SST between children living in the town $(141.1 \pm 111.2 \mathrm{~min} /$ day $)$ and in the city $(149.0 \pm 105.4 \mathrm{~min} /$ day $)$ (Table 4). It is interesting that the time spent in front of a screen (such as television, computer, or video game player) was extremely high on weekends. The children spend an average of 3 hours 53 minutes in the town and 4 hours 6 minutes in the city in SST at weekends.

MVPA (min/day) and SST (min/day) weakly correlated with children's anthropometric data (Table 5). MVPA showed weakly significant negative relationships with body weight $(\mathrm{r}=-0.095$, $\mathrm{p}=0.049)$, BMI $(\mathrm{r}=-0.116, \mathrm{p}=0.017)$ and body fat $(\mathrm{r}=-0.129$, $\mathrm{p}=0.010)$. SST demonstrated very weak positive correlation with the children's age $(r=0.097, p=0.043)$ and body height $(r=0.105$, $\mathrm{p}=0.039$ ).

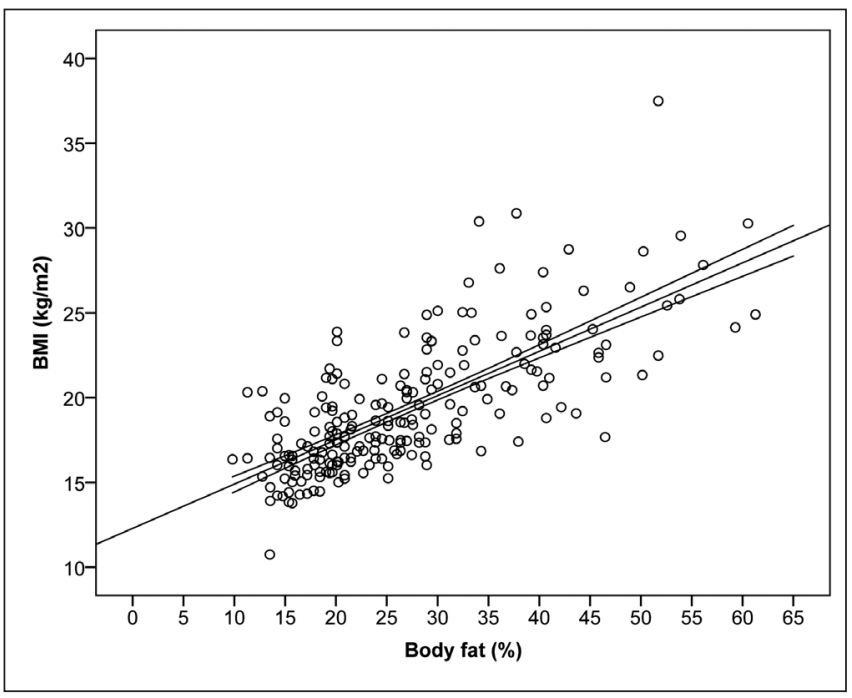

Fig. 3. Correlation between children's body fat (\%) and body mass index $\left(B M I, k g / m^{2}\right)(r=0.723, p<0.001)$.

MVPA (min/day) had strong positive correlation with the energy expenditure (MET-min/day) of the children studied ( $\mathrm{r}=$ $0.945, \mathrm{p}<0.001$ ) (Fig. 2). Strong positive correlation was also found between the children's body fat $(\%)$ and BMI $(r=0.723$, $\mathrm{p}<0.001$ ) (Fig. 3).

\section{DISCUSSION}

Analysis of the anthropometric data of children studied showed a higher prevalence of overweight and obesity in children living in the town $(25.5 \%)$ than in children living in the city $(18.6 \%)$, but this difference was not statistically significant $(p=0.171)$. Researchers in the USA and Canada $(8,9)$ assessed the prevalence of overweight and obesity in children living in different environments and found that overweight was more prevalent among rural than urban children. The prevalence study in Greece (26) revealed that childhood obesity rates were $1.4 \%$ higher in rural areas than

Table 5. Correlations between MVPA (min/day), SST (min/day), age (years), and anthropometric data in children

\begin{tabular}{|l|c|c|c|c|}
\hline \multirow{2}{*}{} & \multicolumn{2}{|c|}{ MVPA (min/day) } & \multicolumn{2}{c|}{ SST (min/day) } \\
\cline { 2 - 5 } & $\mathrm{r}$ & $\mathrm{p}$-value & $\mathrm{p}$-value \\
\hline Age (years) & -0.001 & 0.975 & 0.097 & $0.043^{*}$ \\
\hline Weight $(\mathrm{kg})$ & -0.095 & $0.049^{*}$ & -0.018 & 0.725 \\
\hline Height $(\mathrm{cm})$ & -0.016 & 0.750 & 0.105 & $0.039^{*}$ \\
\hline BMl $\left(\mathrm{kg} / \mathrm{m}^{2}\right)$ & -0.116 & $0.017^{*}$ & -0.075 & 0.145 \\
\hline WC $(\mathrm{cm})$ & -0.079 & 0.109 & -0.017 & 0.750 \\
\hline HC $(\mathrm{cm})$ & -0.074 & 0.133 & -0.010 & 0.846 \\
\hline WHR & -0.036 & 0.466 & 0.002 & 0.973 \\
\hline Triceps SFT (mm) & -0.078 & 0.118 & -0.009 & 0.864 \\
\hline Subscapular SFT (mm) & -0.054 & -0.277 & -0.023 & 0.548 \\
\hline Body fat (\%) & -0.129 & $0.010^{*}$ & 0.660 \\
\hline
\end{tabular}


in urban areas for children of both genders $(\mathrm{p}<0.05)$ aged $10-12$ years. The prevalence of overweight (including obese) was $40.2 \%$ for Greek rural children and $38.5 \%$ for Greek urban children.

In general, the current study revealed a higher prevalence of overweight and obesity in Eastern Lithuanian children than other similar studies in this country. A study of schoolchildren in the five biggest cities and surrounding settlements in Lithuania in 2000-2002 showed that the prevalence of overweight and obesity was $11.50 \%$ and $13.62 \%$ for $7-13$ years old girls and boys, and $6.60 \%$ and $9.50 \%$ for $14-18$ years old girls and boys, respectively (27). The international report from HBSC 2009-2010 survey (28) showed that the prevalence of overweight and obesity in 15 years old Lithuanians was less than 10\% for girls and $10-14 \%$ for boys. The significant difference between findings on the prevalence of overweight and obesity in our study and earlier national Lithuanian studies shows the increasing tendency in the prevalence of overweight and obesity in Lithuanian children.

Analysis of physical activity revealed that children living in the town engaged in an average of $9.3 \mathrm{~min} /$ day less MVPA than children living in the city $(\mathrm{p}=0.050)$. Furthermore, it was found that energy expenditure during physical activities of children living in the town was on an average of 33.2 MET-min/day lower than of the children living in the city $(p=0.069)$.

These findings are in contrast with the study by Ogunleye et al., where the authors found that adolescents from towns and surrounding areas in the Eastern England were more physically active than urban dwellers (18). These authors concluded that towns and surrounding areas with mixed areas of rural and urban land use appear to facilitate and sustain physical activity in both children and adolescents.

Many other studies reported differences between the physical activity of children in rural and urban areas. A study in Greece conducted by Tambalis et al. (26) showed that rural children had a significantly higher total physical activity ( $138 \pm 60 \mathrm{~min} /$ day $)$ than urban children $(118 \pm 56 \mathrm{~min} /$ day $)(\mathrm{p}<0.001)$ and more frequently met physical activity guidelines than their urban counterparts, despite a higher prevalence of obesity (26). Huang et al. (29) investigated the influence of the perceived environment in the neighbourhood on physical activity among schoolchildren in urban and rural areas in Taiwan. The authors reported that there was a difference in accessibility to places for physical activity between urban and rural areas, with urban children reporting greater accessibility. The urban children reported more physical activity after school, on holidays and at weekends and also in total amount of physical activity compared with rural children (29). However, all these findings only prove that suburban areas and towns are often neglected in research, and perhaps the prevention of childhood obesity and physical inactivity in these areas should be a priority.

The study results also showed that the optimal cut-off value of moderate to vigorous physical activity (MVPA) in the children studied was $65 \mathrm{~min} /$ day, which is close to the international MVPA guidelines: the World Health Organization recommends (30) that school-aged children and youth accumulate at least 60 minutes of moderate to vigorous intensity physical activity (MVPA) every day for health benefits.

The analysis of sedentary screen time did not show a significant difference in SST between the town $(141.1 \pm 111.2 \mathrm{~min} /$ day $)$ and the city $(149.0 \pm 105.4 \mathrm{~min} /$ day $)$ children $(\mathrm{p}=0.350)$. However, an interesting finding was that the time spend in front of a screen was extremely high on weekends.

The correlation analysis revealed that MVPA weakly correlated with body weight $(\mathrm{r}=-0.095, \mathrm{p}=0.049)$, BMI $(\mathrm{r}=-0.116$, $\mathrm{p}=0.017)$ and body fat $(\mathrm{r}=-0.129, \mathrm{p}=0.010)$. SST very weakly correlated with age $(r=0.097, p=0.043)$ and body height $(r=0.105, p=0.039)$, meaning that older children spend more time in front of the screen than younger children.

Cross-sectional studies examining the relationship between various measures of body fat and physical activity in children have usually indicated a negative relationship between activity levels and body fat (31). Some studies however show evidence that screen time is more strongly associated with overweight and obesity in childhood than physical activity. Ortega et al. (32) reported that sedentary activities are associated with adiposity in adolescents. These authors found that sedentary activities were independently and directly related to waist circumference in both boys and girls $(\mathrm{p} \leq 0.05)$ and to BMI in boys $(\mathrm{p} \leq 0.05)$, while no relationship was found between leisure-time physical activity and BMI or waist circumference. Stamatakis et al. (33) found that $\mathrm{TV}$ watching, but no other form of screen time (using a personal computer or playing electronic games), was positively associated with two common adiposity markers among Portuguese children. A longitudinal study carried out in the USA by Mitchell et al. (34) provided evidence that spending more time in objectively measured sedentary behaviour is associated with greater increases in BMI during childhood. Importantly, these observed associations were independent of time spent in MVPA (34).

\section{The Strength and Limitations of the Study}

In this study, children's physical activity, sedentary screen time and the prevalence of obesity and overweight were compared in two different living environments - town and city areas. This division of the living environments, including town area as a discrete classification, enabled us to investigate an area which is often neglected in these types of studies. This is the strength of the study.

The main limitation of the study is the absence of research in the rural area.

\section{CONCLUSIONS}

A higher prevalence of overweight and obesity was found in children living in the town (25.5\%) compared with children living in the city $(18.6 \%)$. The children living in the town engaged in an average of $9.3 \mathrm{~min} /$ day less moderate to vigorous physical activity and had 33.2 MET-min/day lower energy expenditure than children living in the city. The children's moderate to vigorous physical activity had weak negative relationships with body weight, BMI, and body fat. Sedentary screen time had a very weak positive correlation with the children's age and body height.

Our study results emphasize the need of preventive strategies on children overweight and obesity in Lithuania especially in town environment (for instance, health-enhancing physical activity programmes at school and community level). In further studies we suggest to include the assessment of other lifestyle factors (such as nutrition, psychosocial factors, etc.) influencing the prevalence of overweight and obesity in children in different settings. 


\section{Acknowledgement}

Sincere thanks to Mrs. Karen Purves for her assistance with the English language.

\section{Conflict of Interest}

None declared

\section{REFERENCES}

1. Daniels SR, Arnett DK, Eckel RH, Gidding SS, Hayman LL, Kumanyika S, et al. Overweight in children and adolescents: pathophysiology, consequences, prevention, and treatment. Circulation. $2005 \mathrm{Apr}$ 19;111(15):1999-2012.

2. Hills AP, King NA, Armstrong TP. The contribution of physical activity and sedentary behaviours to the growth and development of children and adolescents: implications for overweight and obesity. Sports Med. 2007;37(6):533-45.

3. Jiménez-Pavón D, Kelly J, Reilly JJ. Associations between objectively measured habitual physical activity and adiposity in children and adolescents: Systematic review. Int J Pediatr Obes. 2010;5(1):3-18.

4. Strong WB, Malina RM, Blimkie CJ, Daniels SR, Dishman RK, Gutin B, et al. Evidence based physical activity for school-age youth. J Pediatr. 2005 Jun;146(6):732-7.

5. Rey-López JP, Vicente-Rodríguez G, Biosca M, Moreno LA. Sedentary behaviour and obesity development in children and adolescents. Nutr Metab Cardiovasc Dis. 2008 Mar;18(3):242-51.

6. Basterfield L, Adamson AJ, Frary JK, Parkinson KN, Pearce MS, Reilly JJ; Gateshead Millennium Study Core Team. Longitudinal study of physical activity and sedentary behavior in children. Pediatrics. 2011 Jan;127(1):e24-30.

7. Hanson MD, Chen E. Socioeconomic status and health behaviors in adolescence: a review of the literature. J Behav Med. 2007 Jun;30(3):263-85.

8. Liu J, Bennett KJ, Harun N, Probst JC. Urban-rural differences in overweight status and physical inactivity among US children aged 10-17 years. J Rural Health. 2008 Fall;24(4):407-15.

9. Ismailov RM, Leatherdale ST. Rural-urban differences in overweight and obesity among a large sample of adolescents in Ontario. Int J Pediatr Obes. 2010 Aug;5(4):351-60.

10. Hodgkin E, Hamlin MJ, Ross JJ, Peters F. Obesity, energy intake and physical activity in rural and urban New Zealand children. Rural Remote Health. 2010 Apr-Jun;10(2):1336.

11. Sandercock G, Angus C, Barton J. Physical activity levels of children living in different built environments. Prev Med. 2010 Apr;50(4):193-8

12. Plotnikoff RC, Bercovitz K, Loucaides CA. Physical activity, smoking, and obesity among Canadian school youth. Comparison between urban and rural schools. Can J Public Health. 2004 Nov-Dec;95(6):413-8.

13. Tremblay MS, Barnes JD, Copeland JL, Esliger DW. Conquering childhood inactivity: is the answer in the past? Med Sci Sports Exerc. 2005 Jul;37(7):1187-94.

14. Loucaides CA, Plotnikoff RC, Bercovitz K. Differences in the correlates of physical activity between urban and rural Canadian youth. J Sch Health. 2007 Apr;77(4):164-70

15. Dollman J, Norton K, Tucker G. Anthropometry, fitness and physical activity of urban and rural South Australian children. Pediatr Exerc Sci. 2002;14(3):297-312.

16. Booth ML, Okely AD, Chey T, Bauman A. Patterns of activity energy expenditure among Australian adolescents. J Phys Activ Health. 2004;1(3):246-58.
17. Kristjansdottir G, Vilhjalmsson R. Sociodemographic differences in patterns of sedentary and physically active behavior in older children and adolescents. Acta Paediatr. 2001 Apr;90(4):429-35.

18. Ogunleye AA, Voss C, Barton JL, Pretty JN, Sandercock GR. Contrasting physical activity patterns in children and adolescents living in differing environments in the U.K. Scand J Public Health. 2011 Nov;39(7):696703

19. Shearer C, Blanchard C, Kirk S, Lyons R, Dummer T, Pitter R, et al. Physical activity and nutrition among youth in rural, suburban and urban neighbourhood types. Can J Public Health. 2012 Jul 26;103(9 Suppl 3):eS55-60.

20. World Health Organization. Growth reference 5-19 years. BMI-for-age (5-19 years) [Internet]. Geneva: WHO; 2015 [cited 2015 Aug 21]. Available from: http://www.who.int/growthref/who2007_bmi_for_age/en/ index.html.

21. Seidel HM, Ball JW, Dains JE, Flynn JA, Solomon BS, Stewart RW Mosby's guide to physical examination. 7th ed. St. Louis: Mosby/Elsevier; 2011.

22. Lohman TG, Roche AF, Martorell R, editors. Anthropometric standardization reference manual. Champaign, IL: Human Kinetics Books; 1988.

23. Slaughter MH, Lohman TG, Boileau RA, Horswill CA, Stillman RJ, Van Loan MD, et al. Skinfold equations for estimation of body fatness in children and youth. Hum Biol. 1988 Oct;60(5):709-23.

24. Corder K, van Sluijs EM, Wright A, Whincup P, Wareham NJ, Ekelund U Is it possible to assess free-living physical activity and energy expenditure in young people by self-report? Am J Clin Nutr. 2009 Mar;89(3):862-70.

25. Ridley K, Ainsworth BE, Olds TS. Development of a compendium of energy expenditures for youth. Int J Behav Nutr Phys Act. 2008 Sep $10 ; 5: 45$.

26. Tambalis KD, Panagiotakos DB, Kavouras SA, Papoutsakis S, Sidossis LS. Higher prevalence of obesity in Greek children living in rural areas despite increased levels of physical activity. J Paediatr Child Health. 2013 Sep;49(9):769-74

27. Tutkuviene J. Body mass index, prevalence of overweight and obesity in Lithuanian children and adolescents, 1985-2002. Coll Antropol. 2007 Mar;31(1):109-21.

28. Currie C, Zanotti C, Morgan A, Currie D, de Looze M, Roberts C, et al. Social determinants of health and well-being among young people: Health Behaviour in School-Aged Children (HBSC) study: international report from the 2009/2010 survey. Health policy for children and adolescents, no. 6. Copenhagen: WHO Regional Office for Europe; 2012.

29. Huang SJ, Hung WC, Sharpe PA, Wai JP. Neighborhood environment and physical activity among urban and rural schoolchildren in Taiwan. Health Place. 2010 May;16(3):470-6.

30. World Health Organization. Global recommendations on physical activity for health. Geneva: WHO; 2010.

31. Ruiz JR, Ortega FB. Physical activity and cardiovascular disease risk factors in children and adolescents. Curr Cardiovasc Risk Rep. 2009;3(4):281-87.

32. Ortega FB, Tresaco B, Ruiz JR, Moreno LA, Martin-Matillas M, Mesa JL, et al.; AVENA Study Group. Cardiorespiratory fitness and sedentary activities are associated with adiposity in adolescents. Obesity (Silver Spring). 2007 Jun;15(6):1589-99.

33. Stamatakis E, Coombs N, Jago R, Gama A, Mourão I, Nogueira H, et al. Associations between indicators of screen time and adiposity indices in Portuguese children. Prev Med. 2013 May;56(5):299-303.

34. Mitchell JA, Pate RR, Beets MW, Nader PR. Time spent in sedentary behavior and changes in childhood BMI: a longitudinal study from ages 9 to 15 years. Int J Obes (Lond). 2013 Jan;37(1):54-60. 